\title{
Antonio José Cavanilles y la Historia Natural francesa: del Curso de Valmont de Bomare a la Crítica del Método de A.L. de Jussieu*
}

\author{
FRANCISCO PELAYO \\ MARCELO FRÍAS
}

\section{Introducción}

Las relaciones hispano-francesas durante la segunda mitad del siglo XVIII estuvieron marcadas en el campo científico por una doble línea. De un lado, y en consonancia con la situación política, hubo una confluencia de intereses frente a la política de Inglaterra. Por otro, se mantuvo una cierta desconfianza desde el lado español hacia los franceses especialmente desde los responsables de la política española en temas científicos.

El secular interés de Francia por el continente americano había dado lugar a una situación de mutuo recelo entre españoles y franceses. Del lado español, la desconfianza alcanzó niveles muy altos a raíz del desvío de materiales botánicos que realizó hacia París Joseph Dombey (1742-1794) —el botánico francés de la expedición hispanofrancesa al Virreinato del Perú y Chiley que dio lugar posteriormente a lo que se ha conocido como el «affaire l'Héritier" ${ }^{1}$.

Pero al mismo tiempo, Francia era un centro clave para la ciencia, donde se vivía con apasionamiento el debate sobre las nuevas concepciones relacionadas con las ciencias de la vida. En esta línea, París aparece como lugar pri-

\footnotetext{
* Trabajo realizado en el marco del Proyecto de la DGICYT PB 91-0068.
} 


\section{FRANCISCO PELAYO Y MARCELO FRIAS}

vilegiado de encuentro y difusión de las nuevas incorporaciones en el campo del saber científico. No es de extrañar, por tanto, que los naturalistas -o aspirantes a serlo- de toda Europa tuvieran una especial predilección por escoger la capital francesa como destino para completar su formación.

España tomó parte en esa dinámica de movilidad científica. La política ilustrada de fomentar los viajes al extranjero de pensionados pudo servir, en gran medida, de referencia en la decisión del duque del Infantado de establecerse en París. Pero la cuestión que nos interesa tiene más que ver con la dinámica científica entre dos comunidades. En este sentido nos parece interesante acercarnos a las actividades de Antonio José Cavanilles (1745-1804) relacionadas con su etapa francesa. Sus intereses científicos, su formación y su postura final frente a las enseñanzas recibidas van a ser las líneas que nos van a servir de apoyo en un posterior intento de establecer un estudio comparativo entre dos maneras de entender la botánica.

Cavanilles, por sus contribuciones al conocimiento de la taxonomía botánica, puede ser considerado como el más importante naturalista sistemático español del período ilustrado ${ }^{2}$. Su labor en el campo de la botánica ha sido resaltado en prácticamente todas sus biografías ${ }^{3}$, destacando especialmente los estudios realizados por E. Alvarez López ${ }^{4}$. Recientemente, con motivo de la publicación de su Hortus Regius Matritensis, obra manuscrita que había quedado inédita, se ha incidido en este aspecto ${ }^{5}$. El presente trabajo pretende continuar esta línea, atendiendo una parcela poco estudiada como es la de las relaciones de Cavanilles con los botánicos franceses, particularmente con Antoine-Laurent de Jussieu, haciendo un primer acercamiento a su correspondencia epistolar. En este sentido resulta bastante llamativo el hecho de

\footnotetext{
1 Sobre L'Heritier puede consultarse CuvieR, G. (1802), «Notice historique sur CharlesLouis L'Héritier», Mémoires de l'Institut National des Sciences et Arts, vol. 4, pp. 39-55. Sobre el «affaire L'Heritier», véase STEELE, Arthur E. (1982), Flores para el Rey. La Expedición de Ruiz y Pavón y la "Flora del Perú" (1777-1788), SERBAL, Barcelona, pp. 150 ss.

2 Prueba de su labor botánica son las descripciones de más de 80 géneros y de 1.000 nombres. Para más información puede consultarse GarILlETI, R. (1993), «Herbarium Cavanillesianum», Fontqueria, XXXVIII, 249 pp.

3 Una relación de estudios sobre Cavanilles puede encontrarse en LóPEZ PIÑERO, J. M. y LóPEz TERRADA, M. L. (1983), "Antonio José Cavanilles (1745-1804). Estudio bibliografico», Cavanilles naturalista de la ilustración 1745-1804, Real Jardín Botánico, Madrid, pp. 72-80. Cf. también su continuación en este volumen de Asclepio.

4 Particularmente el artículo Alvarez LóPEz, E. (1946), «Cavanilles. Ensayo biográficocrítico", Anales del Jardín Botánico de Madrid, 6, pp. 1-64.

${ }^{5}$ Garilleti, R. \& Pelayo, F. (1991), «Las actividades botánicas del naturalista valenciano A. J. Cavanilles», Hortus Regius Matritensis, Cartonajes Suñer y Real Jardín Botánico, Madrid, pp. XI-XXXI y Pelayo, F. and Garillet, F. (1993), "Spanish botany during the Age of Enlightenment: A. J. Cavanilles», Huntia. A journal of Botanical History, 9 (1), pp. 51-69.
} 


\section{ANTONIO JOSE CAVANILLES Y LA HISTORIA NATURAL FRANCESA}

que Cavanilles, que se inició en el estudio de la botánica en París en un ambiente muy crítico con la sistemática linneana, no siguiera en sus trabajos botánicos el método natural propuesto por Jussieu, utilizado para la enseñanza de la botánica en el Jardin des Plantes, y prefiriera, aunque realizando algunas modificaciones, el sistema artificial de Linné. Sin embargo, y en contra de lo que pudiera desprenderse de esta postura, la aparente contradicción no supuso un distanciamiento personal o profesional entre Cavanilles y A.-L. de Jussieu, quienes prolongaron su relación epistolar a lo largo de casi veinte años.

\section{Los cursos de Cavanilles en París}

El 24 de junio de 1777 salieron de Madrid rumbo a la capital francesa la familia y comitiva de los Duques del Infantado y del Marqués del Viso, acompañados de A. J. Cavanilles y de José Viera y Clavijo (1731-1813), quienes iban en calidad de preceptores de los jóvenes nobles. El diario e itinerario del viaje hasta París, localidad a la que llegaron el 13 de agosto, y la estancia en esta ciudad del grupo durante 1777 y parte de 1778, fue recogida por Viera en su Bibliotheca Isleña. Viages a Francia, Flandes, Italia y Alemania, por los años de 1777 a 1781 (Santa Cruz de Tenerife, 1849).

En París, Cavanilles, Viera y Clavijo y sus discípulos empezaron a asistir desde mediados de noviembre de 1777 a los diferentes cursos de ciencias naturales y a las demostraciones experimentales, muy populares entre las clases sociales más elevadas, que se impartían en la capital francesa ${ }^{6}$.

El primer curso, que comenzó el 17 de noviembre, fue el de "Física experimental», impartido por Joseph-Aignan Sigaud de La Fond (1730-1810) en su gabinete de máquinas de la rue de Saint Jacques, al que asistieron cinco españoles: el duque del Infantado, el marqués del Viso, el conde Carlet de Valencia, Cavanilles y Viera ${ }^{7}$. Posteriormente, el 1 de diciembre, se abría el curso de "Química y Mineralogía» de Balthasar Georges Sage (1740-1824), al que asistía tanta gente que Viera comenta que se llenaban tres habitaciones con nobles de ambos sexos, obispos, abades, militares y religiosos ${ }^{8}$. El siguiente curso al que asistieron fue el de "Historia Natural», que con carácter privado

\footnotetext{
${ }^{6}$ Sobre los cursos y los profesores encargados de impartirlos a los que asistió Cavanilles puede consultarse Pelayo, F. y Garilleti, R. (1992), «La formación y actividades botánicas de A. J. Cavanilles», Asclepio, XLIV, pp. 130-132.

7 VIera y ClaviJo, J. (1849), Bibliotheca Isleña. Viages a Francia, Flandes, Italia y Alemania, por los años de 1777 a 1781, Santa Cruz de Tenerife, p. 83.

8 Viera y ClaviJo (1849), pp. 82-87.
} 


\section{FRANCISCO PELAYO Y MARCELO FRIAS}

impartía Jacques Christophe Valmont de Bomare (1731-1807) en su casa de la rue de la Verrerie.

Jacques Valmont de Bomare había estudiado farmacia en Rouen, su localidad natal, desde donde pasó a París en torno a 1750. Fue comisionado por el gobierno para visitar gabinetes, minas y talleres metalúrgicos de distintos países europeos. A su vuelta a la capital francesa comenzó sus cursos de historia natural. Su más importante contribución a esta última disciplina fueron los volúmenes de su Dictionnaire raisonné universel d'histoire naturelle (París, 1764), que alcanzó varias ediciones durante el siglo XVIII. En la biblioteca de Cavanilles se encuentra la edición de 1775, que comprende 9 volúmenes. Se puede destacar también su obra Traité de Minéralogie (París, 1762).

Anuncios de la apertura de los primeros cursos de Valmont de Bomare se publicaron en julio y diciembre de 1757 en las Observations periodiques sur la Physique, l'Histoire Naturelle et les Arts ou Journal des Sciences et Arts, revista editada por Jacques Gautier Dagoty (1717-1785). En ellos se hacía especial mención al carácter aplicado que Bomare daba a su curso. Así, al referirse al apartado dedicado a la botánica, se mencionaba «el estudio de maderas empleadas en ebanistería y carpintería, de plantas tintóreas, de especies empleadas para barnices, además de modo y tiempo de recolección, del comercio y de las alteraciones a las que eran sometidas las plantas para poder extraer de ellas alguna utilidad" 9 .

Los cursos de Historia Natural tuvieron mucho éxito de público, impartiéndolos Bomare en su gabinete durante más de tres décadas ${ }^{10}$. Eran los más concurridos en el campo de las ciencias naturales, por lo que parecía ser el más recomendable para iniciarse en una formación básica en biología y mineralogía. De todas formas, se encuentran juicios críticos acerca de la validez científica del programa de Bomare. Tal fue el caso de Eugenio Izquierdo (?-1813), pensionado español en París que fue director del Real Gabinete de Historia Natural de Madrid. En una carta de 1773 dirigida a Pedro Franco Dávila, tras describir en tonos elogiosos del curso química impartido por Rouelle, le comentaba en relación al curso de Bomare:

\footnotetext{
9 «Cours d'Histoire Naturelle Appliquée aux Arts et aux Métiers. Par M. Bomare de Valmont", Observations periodiques sur la Physique, l'Histoire Naturelle et les Arts ou Jornal des Sciences et Arts, París, 1757, t. III, p. 65. Se anunciaba la apertura el 16 de julio de un curso público impartido por el boticario Bomare de Valmont, en el que se trataría de los tres reinos de la naturaleza: mineral, vegetal y animal. En el mismo tomo III, correspondiente al mes de diciembre, páginas 450-451, se anunciaba el «Second Cours Public d'Histoire Naturelle Concernant les Minéraux, les Vegétaux et les Animaux relativement aux Arts et Métiers".

10 LaIssus, Y. (1986), "Les cabinets d'Histoire Naturelle», en Taton, R. Enseignement et diffusion des sciences en France au dix-huitième siècle, París, p. 665.
} 


\title{
ANTONIO JOSE CAVANILLES Y LA HISTORIA NATURAL FRANCESA
}

\begin{abstract}
"Del curso de Historia Natural no puedo contar tantas ventajas. M. Bomare, que lo comenzó el 4 de diciembre, da tres lecciones por semana los lunes, miércoles y viernes, desde las diez y media hasta medio día. Lee muy pocas veces y nadie escribe en su curso, por la rapidez con la que habla. No tiene método propio en sus lecciones; de la Mineralogía de Wallerius, que ha traducido en francés y de su Diccionario de Historia Natural ha sacado todos los materiales para el Reino Mineral. El Vegetal ha comprendido 9 lecciones, en la $1 .^{a}$ ha tratado de raíces y cortezas; en la $2 .^{a}$ de troncos y maderas; en la $3 .^{a}$ de árboles y hierbas; en la $4 .^{a}$ de ramas y hojas; en la $5 .^{a}$ de flores; en la $6 .^{a}$ de frutos; en la $7 .^{\mathrm{a}}$ de simientes; en la $8 .^{\mathrm{a}}$ de jugos y bálsamos y en la $9 .^{\circ}$ de resinas, gomas y azúcares. En todas ha dado mas de curioso que de instructivo y hemos visto un poseedor de cosas singulares, pero escaso de ideas científicas.

En fin, su curso no me servirá más que para familiarizarme con los objetos, como Vd. me lo previno.» ${ }^{11}$
\end{abstract}

\section{El curso de "Historia Natural» de J. Valmont de Bomare}

La apertura del curso al que asistió el grupo de Cavanilles tuvo lugar el 6 de diciembre de 1777 y la finalización del mismo, cuatro meses después: el 11 de abril de 1778. En total asistieron a cerca de medio centenar de clases. Gracias a la descripción de Viera podemos reconstruir el escenario que Cavanilles encontró en este curso. Las lecciones tenían lugar en el propio gabinete de Valmont de Bomare, que comprendía dos salas "muy bien iluminadas" y en las que se tenía acceso a distintas materiales y objetos representativos de Historia Natural.El ambiente que se recreaba en torno a estas lecciones sobre el conocimiento de la naturaleza debía recordar una atmósfera similar a la originada en una secta religiosa, ya que como decía Viera:

«...el aparato del gabinete, el concurso, la larga mesa que se veía en el centro cubierta con muestras de las producciones mas exquisitas de la Historia Natural; el orador a la cabeza del concurso, ya sentado y ya de pie en una especie de nicho que hacía la pared de la sala; y sobre todo lo patético de su sermón, todo infundía no se qué género de entusiasmo o idea religiosa y sublime de la naturaleza, que se miraba allí, con templo, culto, panegirista, fieles etc.» ${ }^{12}$

La presentación del curso puede servirnos como orientativa en la comprensión de la rápida adscripción que Cavanilles -formado especialmente en

\footnotetext{
11 Archivo del Museo Nacional de Ciencia Naturales de Madrid (AMNCN) Leg. n. ${ }^{\circ}$; Carp. 19. Véase Calatayud, M. A. (1987), Catálogo de documentos del Real gabinete de Historia Natural (1752-1786), CSIC, Madrid, Referencia 121.

12 Viera y Clavijo (1849), p. 89.
} 
Filosofía y Teología - tuvo hacia la Historia Natural. Así, Viera nos recuerda el comienzo del discurso de Bomare con recomendaciones - "por ameno»al estudio de la naturaleza. Un acercamiento al mundo natural donde se resaltan sus utilidades y placeres, describiendo «el estado actual» del globo terráqueo y del relieve de la superficie terrestre, sin olvidar los fenómenos que actúan sobre ella.

En estos comienzos del curso no encontramos también con referencias a los autores que habían tratado del estudio de la naturaleza, desde Aristóteles hasta Buffon.

El curso quedó estructurado durante los siguientes meses en tres bloques definidos: uno dedicado a la geología y mineralogía, otro al mundo. vegetal y un tercero a la zoología.

Con la exposición de su ideas geológicas y mineralógicas Bomare inició las sesiones que impartió a lo largo del mes de diciembre de 1777 y que se alargaron durante el mes de enero y primeros días de febrero de 1788 . "Método y claridad», como recordaba Viera, en un curso que se iniciaba con una primera clase dedicada a los cuatro elementos de los antiguos, y que en las semanas posteriores se centraron en abordar un completo abanico de materiales, fenómenos y disposiciones en relación al globo terráqueo. Así, nos encontramos con comentarios sobre la estructura de la tierra y sobre los materiales terrestres que se encontraban dispuestos en estratos; alusiones a los fósiles marinos, lacustres y terrestres que se encontraban en ellos y a los fenómenos geológicos que habían actuado sobre el relieve terrestre. Tema que se completaba con comentarios sobre las etapas orogénicas antidiluviana, primitiva y actual, los volcanes y los distintos accidentes geográficos: ríos, valles, islas, cabos, istmos. Seguidamente, Bomare analizaba diferentes tipos de aguas dispuestas en su mesa de demostraciones: de fuente, de río, de pozo, de lluvia, del océano, del Mediterráneo, del Mar Muerto, de lago, de termas minerales, ácidas, sulfurosas, destilada en un alambique, etc. Por último, la discusión se centraba sobre componentes inorgánicos: tierra, arcilla, greda, arenas, piedras (arcillosas, cretosas, yesosas, calcáreas, silex, cuarzo, piedras volcánicas, lavas, piedras preciosas, pórfido, granito etc.). Una vez concluido este apartado dedicado a la Litología, Bomare pasaba a explicar las sales (simples y compuestas o neutras), metales, semimetales, para terminar con los fósiles y las petrificaciones ${ }^{13}$. Estas lecciones debieron de ser completadas con el estudio de los propios materiales, pues en aquellas mismas semanas le compraron a Bomare una colección de muestras del reino mineral.

El 12 de febrero Valmont de Bomare dio comienzo sus lecciones sobre el reino vegetal, tratando primeramente sobre las diferentes clases de raíces:

\footnotetext{
13 Idem, pp. 89-101.
} 
contrayerba, hipecacuana, jalapa, gengibre, zarzaparrilla... Dividía a las plantas por su tamaño en arbustillos, arbustos, árboles, hablando del tronco, de las maderas preciosas, de las plantas parásitas. Abordaba a continuación los órganos, los injertos, la poda, algunas cuestiones de fisiología vegetal relacionadas con el movimiento y el sueño de las plantas, dedicando una clase a los frutos. En relación a las flores, comentaba su organización, sexos, propagación, "adulterios" y «bastardías" y explicaba los sistemas botánicos de Linné y Tournefort. Continuaba sus lecciones sobre los vegetales describiendo las semillas y los granos de las plantas, los bálsamos, gomas y resinas, para terminar hablando de las plantas venenosas, féculas y criptógamas ${ }^{14}$.

A comienzos de marzo de 1778, un "bello discurso» le sirvió a Valmont de Bomare de introducción a la zoología. Algunas plantas marinas, decía, se encontraban en el límite que dividía los reinos vegetal y animal: algas, «litophitos», esponjas, madreporas, corales... Describía animales que, comentaba Viera, tenían la capacidad de reproducirse cuando se les cortaba en pedacitos, los animales microscópicos y espermáticos, así como los sistemas ideados por los naturalistas para explicar su generación. A continuación describía los equinodermos, moluscos, crustáceos e insectos, para dedicar las siguientes tres clases a las aves la primera, a los cetáceos, reptiles y anfibios la segunda y a los cuadrúpedos y cuadrúmanos (los monos) la tercera $^{15}$.

Estas lecciones de gabinete fueron completadas, además, con el contacto con la naturaleza, incluyendo en la parte final del curso una salida al campo. Tras dedicar una clase a repasar nociones de mineralogía, el grupo de asistentes realizó dicha salida capitaneados por el maestro. Se dirigieron para estudiar los minerales "in situ" al cerro de Montmartre, en donde, según la narración de Viera, Bomare se debía sentir como el apóstol de la Naturaleza:

"Valmont de Bomare se colocó en una peña y desde allí como predicador y en ademán de misionero poseído de entusiasmo y de elocuencia natural, teniendo una vara larga en la mano, iba señalando el orden de los materiales y la calidad de ellos.»16

El 11 de abril de 1778 Valmont de Bomare culminó sus lecciones con una última recopilación de los temas tratados anteriormente sobre el reino mineral. Con ello se daba por finalizado el curso de Historia Natural, que terminó con las correspondientes despedida y pago de una cantidad por cada asistente.

14 Idem, pp. 101-103.

15 Idem, pp. 103-108.

16 Idem., pp. 109. 
La presentación de los cursos de Bomare nos permite apreciar un panorama lo suficientemente completo del mundo natural que, sin duda, clarificó las inquietudes de Cavanilles. Unas precisas pero al mismo tiempo amplias lecciones que abordaban las principales cuestiones de los tres grandes bloques en que estaban divididos los estudios naturales: animal, mineral y vegetal. La asistencia al curso de Bomare tuvo que proporcionar, por tanto, a Cavanilles al menos unas mínimas nociones básicas de historia natural. A pesar de ello, y aunque Bomare hacía referencia a los sistemas de Tournefort y Linné, los conocimientos botánicos, tal como asegura en sus cartas y notas manuscritas el naturalista valenciano, los fue adquiriendo de forma autodidacta.

\section{La formación de un botánico}

Una vez establecido el papel de inductor que debió jugar el curso de Valmont de Bomare, es preciso que nos acerquemos a otras referencias que puedan arrojarnos más luz sobre la formación botánica de Cavanilles.

Cavanilles, en su correspondencia con Viera, señala que el abate de Chaligny, amigo de la familia del duque del Infantado, influyó de alguna manera en su interés por el estudio de la botánica ${ }^{17}$. Fue en torno a 1780 cuando Cavanilles empezó a manifestar un claro interés por esta disciplina. Esta inclinación se vio favorecida por los continuos viajes realizados junto a los duques del Infantado. En ellos, Cavanilles aprovechaba para recolectar plantas de caminos y veredas, para visitar jardines botánicos públicos, como el de Lovaina, y privados, como el del vizconde de Walckiers en Bruselas, y para herborizar en los alrededores de la casa de campo de La Chevrette, lugar de veraneo de los duques. Por esta época - 1782- Cavanilles iba aprovechando, asimismo, para aumentar su bibliografía botánica mediante la compra de obras, como las del médico alemán Christian Jacob Trew (1695-1769) Plantae selectae (1750-1773) y Plantae rariores $(1763-1779)^{18}$, que contenían una rica colección iconográfica de un centenar de plantas iluminadas, además de la Flora Suecica (1745), el Systema Naturae (1745) y los Amoenitates Academicae (1749), todas ellas de Linné19. Dato especialmente significativo este último, pues nos permite constatar cómo, en una fecha en la que prácticamente era

\footnotetext{
17 Cavanilles, [A.] J. (1981), Cartas a José Viera y Clavijo. Introducción y notas de Alejandro Cioranescu, A.C.T., Santa Cruz de Tenerife, pp. 10 y 52.

18 Ambas obras se encuentran en la biblioteca de Cavanilles. Véase Archivo del Real Jardín Botánico, Madrid (ARJB) I, 12, 4, 1.

19 Cf. Cavanilles (1981), p. 59.
} 
un recién llegado a la botánica, Cavanilles ya sentía especial interés hacia la obra del botánico sueco.

Su herbario se vio incrementado en pocos años con las visitas a los jardines de Aremberg, de Cels, de Saint Germain en París, de Triannon, de Versalles, y sus recolecciones en el estanque de Montmorency, al norte de París, y en los alrededores de La Chevrette.

La reputación botánica de Cavanilles se vio favorecida, en gran medida, por las buenas relaciones que supo mantener con los botánicos franceses. Ellos le ayudaron en las identificaciones de sus recolecciones, facilitándole el acceso al rico herbario del jardín botánico de París. Además, bien por la comunicación que mantuvo con alguno de ellos -el caso de A. L. de Jussieu-, o por las críticas que les dedicó - caso de Lamarck - constituyen referentes obligados para comprender su evolución como botánico.

\section{El Jardin des Plantes de París en el período pre-revolucionario.}

A la llegada de Cavanilles a París el organigrama del Jardin des Plantes estaba encabezado por G. L. Leclerc conde de Buffon (1707-1788), que ejercía desde 1739 las funciones de Intendente. En cuanto a la plantilla dedicada a los trabajos botánicos, el profesor titular de esta disciplina era Louis-Guillaume Lemmonier (1717-1799), el Démonstrateur o encargado de demostrar las plantas era Bernard de Jussieu (1699-1777), el director de los cultivos o jefe de las plantaciones del jardín era André Thouin (1747-1824).

Desde los primeros años de la década de los setenta y hasta 1786, fecha en que René Desfontaines (1750-1833) fue nombrado profesor de botánica, Antoine-Laurent Jussieu (1747-1836) fue el suplente de Lemmonier en la enseñanza y de su tío Bernard en las demostraciones.

Por las mismas fechas, comienzos de la década de los setenta, Jean Baptiste de Monet, caballero de Lamarck (1744-1829), se había instalado en París. Comenzó unos inacabados estudios de medicina, para dedicarse en un principio con más éxito a la botánica ${ }^{20}$. Parece que siguió las demostraciones botánicas de Bernard de Jussieu en el jardín botánico ${ }^{21}$. Gracias a la intervención de Buffon, se le nombró en 1781 corresponsal del jardín botánico y luego botánico del Cabinet Royal encargado de los herbarios, logrando ser admitido en la Académie Royales des Sciences de París como botánico adjunto.

\footnotetext{
20 Véase DuRIs, P. (1993), Linné et la France (1780-1850), Librairie Droz, Genève, p. 146.

${ }^{21}$ Cf. LeRoy, J.F. (1971), «La botanique au Jardin des Plantes (1626-1970)», Adansonia, 11 (2), pp. 225-250.
} 
Durante estos primeros años en París, Lamarck trabajó en la redacción de su Flore française, ou description succinte de toutes les plantes naturellement en France, disposée selon une nouvelle méthode d'Analyse, \& à laquelle on a joint la citation de leurs vertus les moins équivoques en Médecine, \& de leur utilité dans les Arts (París, 1778). Este largo título aclara cual eran las intenciones de Lamarck al elaborar su obra: la descripción de la flora francesa siguiendo un método analítico, teniendo en cuenta además las propiedades medicinales de las plantas, así como sus otras posibles utilidades. En esta obra, que alcanzó varias ediciones entre finales del XVIII y principios del XIX, Lamarck siguió una clasificación artificial, empleando un sistema dicotómico de claves que facilitaba las determinaciones ${ }^{22}$.

A partir de 1783, Lamarck se encargó de redactar el apartado dedicado al Dictionnaire de Botanique en la Encyclopédie Méthodique. Lamarck, tal vez presionado por el editor C.J. Panckoucke (1736-1798), seguirá en esta obra el sistema sexual de Linné23. Esto no va a significar su aceptación incondicional de la ortodoxia linneana, puesto que en artículos posteriores se mostrará crítico con el sistema del naturalista sueco, al que reprocha su excesiva preocupación por cuestiones nomenclaturales y limitarse a componer clasificaciones arbitrarias ${ }^{24}$.

Posteriormente, en 1789, también gracias a Buffon, se creó para él el cargo de Botaniste du Roi attaché au Cabinet d'Histoire Naturelle ${ }^{25}$.

La entrada de Antoine-Laurent de Jussieu en el Jardin des Plantes se produjo en torno a $1770^{26}$. Había llegado de Lyon pocos años antes, doctorándose en medicina en la Facultad de París con una tesis en la que comparaba la

\footnotetext{
22 Acerca de la obra botánica de Lamarck véanse DAuDiN, H. (1926-1927), De Linné à Lamarck. Méthodes de la classification et idée de série en botanique et en zoologie (1740-1790), Félix Alcan, París, pp. 188-204 (la edición consultada es una reimpresión de esta obra realizada en 1983 por Éditions des Archives Contemporaines) y DurIs (1993), pp. 146-151. Otros aspectos de su obra pueden consultarse en CORSI, P. (1983), Oltre il mito. Lamarck e le scienze naturali del suo tempo, Il Mulino, Bologna y LAURENT, G. (1987), Paléontologie et évolution en France, 1800-1860. Une histoire des idées de Cuvier et Lamarck à Darwin, CTHS, París:

${ }^{23}$ Así lo expresa Duris (1993) p. 147, quien remite a su vez a BonNET, E. (1890), "Lettres et documents inédits pour servir à l'histoire de la botanique au XVIII ${ }^{\mathrm{e}}$ siècle. V. Traité passé entre Lamarck et les éditeurs de L'Encyclopédie méthodique», Journal de botanique, 4 (9), p. 236.

24 DuRIS (1993), p. 147.

25 Puede verse Laissus, Y. (1986), «Le Jardin du Roi» en Taton, R., op. cit., pp. 287-341.

26 Para la biografía de Antoine-Laurent de Jussieu se pueden consultar BRONGNIART, A. (1837), «Notice historique sur Antoine-Laurent de Jussieu», Annales des Sciences Naturelles, 7, pp. 5-24; Lacroix, A. (1941), "Notice historique sur les cinq Jussieu», Mémoires de l'Académie Royale des Sciences et de l'Institut de France, 63, pp. 34-48 y Michaud, J. FR., Biographie Universelle ancienne et moderne. Nouvelle edition, 1968, t. XXI, Graz, pp. 352-357.
} 


\section{ANTONIO JOSE CAVANILLES Y LA HISTORIA NATURAL FRANCESA}

estructura y funciones de los órganos vegetales con los fenómenos de la vida animal ${ }^{27}$. Su tío Bernard, en un caso claro de nepotismo, aprovechó la circunstancia de que Lemmonier, médico ordinario de Louis XV, se vio obligado a residir en Versalles y dedicarle más tiempo y atención al cuidado de la salud del rey, para colocar a su sobrino y que supliera la ausencia en la capital de Lemmonier.

Durante los primeros cuatro años Antoine-Laurent realizó las demostraciones de las plantas siguiendo la antigua disposición de las escuelas botánicas del jardín, que se remontaba a los tiempos de J. P. de Tournefort. Pero solicitó, y consiguió, de Buffon los fondos necesarios para llevar a cabo trabajos de reorganización, replantación y mejoras, a fin de poder disponer de una nueva escuela. Aprovechó esta circunstancia para establecer lo que él denominaba un método nuevo para la enseñanza de la botánica ${ }^{28}$. El método, fundado en los caracteres más esenciales de los vegetales, estaba basado en las familias de plantas que había establecido desde el año 1758 su tío Bernard en el jardín de Trianon.

A partir de 1774, las demostraciones de plantas en el jardín botánico de París se realizaron según el nuevo plan. A.-L. Jussieu tuvo además el mérito de sustituir la vieja nomenclatura tournefortiana por la de Linné.

Antoine-Laurent expuso el método natural que había estado empleando su tío Bernard en dos memorias presentadas en la Académie Royale des Sciences de París: el «Examen de la famille des Renoncules» ${ }^{29}$, leída en 1773 y que fue determinante en su admisión como botánico adjunto en la Academia de Ciencias de París, y la «Exposition d'un nouvel ordre de plantes adopté dans les démonstrations du Jardin Royal» ${ }^{30}$, que leyó al año siguiente.

Si en la primera de ellas Jussieu desarrolló los principios que se debían seguir para establecer un método natural, que aplicó a la familia de las ranunculáceas, en la segunda, más importante, enunciaba los principios fundamentales de dicho método, la subordinación de los caracteres, aplicado para demostrar las plantas del Jardin du Roi.

En esta segunda memoria Jussieu dividía el reino vegetal en tres grupos: acotiledones, monocotiledones y dicotiledones, según la ausencia o el número de cotiledones, que consideraba el carácter más esencial. La diferente

\footnotetext{
${ }^{27}$ El título de su tesis defendida en 1770 fue An oeconomiam animalem inter et vegetalem analogiae.

28 Jussieu, A. L. (1805), "Notices historiques, sur le Muséum d'Histoire Naturelle», Annales du Muséum d'Histoire Naturelle, VI, pp. 10-11.

29 Publicada en las Mémoires de l'Académie Royale des Sciences, correspondientes al año 1773, París, pp. 214-240.

${ }^{30}$ Mémoires de l'Académie Royale des Sciences, correspondientes al año 1774, París, pp. 175-197.
} 
inserción de los estambres, según que estuvieran colocados por encima, por debajo o alrededor del pistilo, daban lugar a posteriores subdivisiones.

Jussieu, en una clara referencia a la "escala de los seres», comentaba que las plantas se extendían por el globo terráqueo y parecían formar una cadena continua, cuyos extremos eran la hierba más pequeña y el árbol más elevado. Por una gradación insensible se elevaban desde aquella hasta éste, disponiéndose en serie las plantas cuya afinidad estaba marcada por un mayor número de relaciones. Este orden de la Naturaleza, decía Jussieu, presentaba una utilidad muy real, ya que el razonamiento, apoyado siempre en la experiencia, demostraba que aquellas plantas cuyos caracteres coincidían, gozaban también de las mismas propiedades, de manera que a partir del orden natural podría determinarse, a través de los signos externos, sus respectivas virtudes $^{31}$.

Según Jussieu, la Naturaleza dejaba entrever los principios sobre los que descansaba el orden natural, ya que entre todos los caracteres que se encontraban en cada planta, algunos, como las partes de la fructificación, eran esenciales, generales e invariables y constituían la base de dicho orden. Por tanto, los pistilos y los estambres eran tales partes esenciales y principales, ya que concurrían a formar un nuevo individuo ${ }^{32}$.

En su primera exposición de su método de clasificación, A. L. de Jussieu consideró un total de catorce clases:

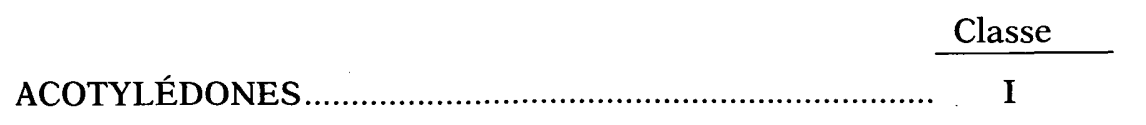

MONOCOTYLÉDONES:

Étamines attachées au support ...................................... II

Étamines attachés au calice.............................................. III

Étamines attachées sur le pistil.................................... IV

\section{DICOTYLÉDONES:}

Apétales:

Étamines attachées au calice ...................................... V

Étamines attachées au support.................................. VI

Monopétales:

Corolle attachée au support ...................................... VII

Corolle attachée au calice ............................................ VIII

\footnotetext{
31 Jussieu (1774), Op. cit., p. 175.

32 Idem., pp. 178-179.
} 


\section{ANTONIO JOSE CAVANILLES Y LA HISTORIA NATURAL FRANCESA}

Corolle attachée sur le pistil:

anthères reunies

IX

anthères distinctes

$\mathrm{X}$

Polypétales:

Étamines \& corolle attachée sur le pistil

XI

Étamines \& corolle attachée au support

XII

Étamines \& corolle attachée au calice

XIII

Irregulières:

Étamines séparées du pistil

$\mathrm{XIV}^{33}$

En una obra posterior más elaborada, Genera Plantarum secundum ordines naturales disposita (París, 1789), Jussieu profundizaba en la clasificación, de manera que cada una de estas clases (añadía una decimoquinta clase dentro de las Dicotiledóneas apétalas) estaban subdivididas en cien órdenes o familias, en las cuales incluyó 1.754 géneros $^{34}$.

Cuando Cavanilles llegó a París, se encontró que las plantas del Jardin $d u$ Roi estaban clasificadas según este método natural propuesto por los Jussieu. Su acceso a este jardín botánico se vio facilitado por A. Thouin ${ }^{35}$, jefe de jardinería en dicha institución científica, quien permitió que Cavanilles pudiera entrar en el jardín a recoger y comprobar los materiales botánicos que le hacían falta para identificar sus ejemplares. Además, Thouin respondía a sus observaciones botánicas y le enviaba las plantas y semillas que Cavanilles le solicitaba.

A Cavanilles, además de permitirle utilizar los herbarios del Jardin des Plantes, le pusieron a su disposición los que se conservaban en el gabinete real, donde, a iniciativa de Buffon, se guardaban las colecciones traídas por Adanson del Senegal y las que contenían plantas exóticas de Oceanía, recogidas en los viajes de circumnavegación por Philibert Commerson (1727-1773) y Pierre Sonnerat (1748-1814)

En París, Cavanilles no sólo se relacionó con los botánicos vinculados al Jardin du Roi, sino también con Michel Adanson (1727-1806). Adanson se había iniciado en el estudio de la botánica con Bernard de Jussieu en el Jardin des Plantes. Su falta de recursos económicos le llevó a aceptar un empleo

\footnotetext{
33 Idem., pág. 188

34 Cf. Cavanilles, A. J. (1800), "Materiales para la historia de la botánica», Anales de Historia Natural, 2 (1), p. 11.

35 Sobre A. Thouin puede consultarse LetouzeY, Y. (1989), Le Jardin des Plantes à la croissée des chemins avec André Thouin (1747-1824), París, Editions du Muséum.
} 


\section{FRANCISCO PELAYO Y MARCELO FRIAS}

de la Compagnie des Indes en el Senegal. Allí, al contacto con la rica variedad de la flora tropical, comprobó las dificultades de aplicar un sistema artificial a la clasificación de las plantas ${ }^{36}$. A su vuelta de Senegal fue nombrado por Louis XV conservador del Jardín de Trianon y publicó su Famille des Plantes (París, 1763). En esta obra Adanson proponía para la clasificación botánica un método natural que considerara el conjunto de todos las partes de las plantas. Era preciso, pues, considerar las raíces, los tallos, las hojas, las flores, los frutos, en resumidas cuentas, todas las partes, cualidades o propiedades y facultades del vegetal. ${ }^{37}$. Adanson representaba entre los botánicos franceses la oposición más fuerte al sistema linneano.

Pues bien, gracias a sus excursiones, relaciones con los botánicos, visitas a jardines, estudio de los herbarios de botánicos y viajeros franceses a tierras de ultramar y con las semillas enviadas desde España por Viera, Antonio Palau (1734-1793), profesor en el jardín botánico de Madrid, y Cándido M. ${ }^{\mathrm{a}}$ Trigueros (1736-1798), Cavanilles empezó en 1784 a trabajar en su primera monografía botánica, en concreto, sobre la clase Monadelphia.

Es en este momento, finales de 1784, cuando comienza su relación epistolar con Antoine-Laurent de Jussieu.

\section{La relación de Cavanilles con A. L. de Jussieu}

El volumen que se conserva del intercambio epistolar entre los dos naturalistas alcanza un total de setenta cartas, custodiadas en el Laboratoire de Phanérogamie del Muséum National d'Histoire Naturelle (París) y. en el. Archivo del Real Jardín Botánico (Madrid), que abarcan un período de 18 años, tiempo que duró esta relación ${ }^{38}$.

La correspondencia se inicia en noviembre de 1784, con una carta desde Yssy, en la que Cavanilles comentaba a Jussieu su trabajo sobre el género Sida, con materiales del jardín botánico parísino, bajo el beneplácito de Thouin, y le solicitaba permiso para consultar su herbario. A partir de este primer contacto se inició la relación entre ambos naturalistas. Una de las primeras actuaciones de Jussieu en favor de Cavanilles fue su apoyo, junto con Lamarck y A.D. Fougeroux de Bondaroy (1732-1789), en el nombramiento del naturalista valenciano como miembro correspondiente de la Academia de Ciencias de París.

\footnotetext{
36 DurIs (1993), p. 140

37 Adanson, M. (1763), Famille des Plantes, París, I, p. CLV.

38 Agradecemos la colaboración de Mme. Mollet (Laboratoire de Phanérogamie, MNHN) y de Pilar de San Pío (Archivo del Real Jardín Botánico) en la consulta de los correspondientes documentos.
} 
Podemos establecer dos grandes periodos en las relaciones epistolares entre ambos botánicos. Una primera etapa, comprendida entre finales de 1784 y 1789, fecha en que Cavanilles vuelve definitivamente a España, y una segunda que se alargaría desde la vuelta a España en 1789 hasta 1802.

\section{La etapa francesa}

El grueso de la correspondencia de la primera etapa versará sobre los trabajos botánicos del abate, que iniciaba sus estudios sobre la clase Monadelphia. La determinación tomada respecto a este trabajo quedaba señalada en el envío que Cavanilles hizo a José Celestino Mutis en mayo de 1786: «Vuesamerced verá en el prólogo de mi segunda disertación el vasto objeto que me he propuesto, que es de examinar a fondo la Monadelphia». Objetivo al que acompañảba una relación precisa sobre las tareas a realizar: «rectificar los caracteres defectuosos de los géneros, crear otros y aumentar el número de especies, grabándolas todas sobre los dibujos que yo mismo hago» ${ }^{39}$.

En estos primeros años Cavanilles había recibido de Jussieu ayuda en las dudas que se le presentaban en la determinación de diversos géneros. El botánico francés le había dado su opinión y proporcionado documentación bibliográfica botánica ${ }^{40}$. Además, Cavanilles había hecho partícipes de su trabajo a otra serie de científicos a los que mencionaba como «amigos»: los también franceses Lamarck y Thouin, el inglés Joseph Banks (1740-1820) y el sueco Carl Peter Thunberg (1743-1828) ${ }^{41}$.

La publicación de la Monadelphia, cuyos dos primeros tomos fueron presentados en la Académie Royale des Sciences de París por Adanson, Jussieu, Lamarck y A. D. Fougeroux de Bondaroy, fue muy bien recibida por los botánicos europeos.

La figura de Linné apareció también a menudo en las relaciones de Cavanilles con Jussieu. Aún reconociendo la importancia de la obra de Linné, Cavanilles comentaba a su correspondiente francés algunos de los errores que

\footnotetext{
39 Carta de Antonio José Cavanilles a José Celestino Mutis, París, 1 de mayo de 1786; HERNÁNDEZ DE AlBA, Guillermo (Comp.) (1983), Archivo epistolar del sabio naturalista don José Celestino Mutis, Instituto Colombiano de Cultura Hispánica, Bogotá, tomo III, n. ${ }^{\circ}$ 123. Cavanilles mantuvo unas relaciones especialmente cordiales con José Celestino Mutis. Ambos, junto con Antonio José Zea, fomaron un frente crítico contra el grupo de Casimiro Gómez Ortega; FríAs NúÑEz, Marcelo (1994), Tras El Dorado Vegetal. José Celestino Mutis y la Real Expedición Botánica del Nuevo Reino de Granada. (1783-1808), Diputación Provincial, Sevilla.

40 Carta de Jussieu a Cavanilles, 23 de enero de 1786; ARJB, XIII, 3, 32, 3.

41 Carta de Cavanilles a Mutis, París, 1 de mayo de 1786; Hernández de Alba, G. (Comp.) (1983), tomo III, n. ${ }^{\circ} 123$.
} 


\section{FRANCISCO PELAYO Y MARCELO FRIAS}

en su opinión había cometido el botánico sueco. Pero se trata de una crítica de la que el propio Cavanilles se lamenta, en la medida que el botánico sueco sigue siendo una referencia obligada en sus trabajos: «C'est dommage que ce savant tombe si souvent dans des erreurs coupables», observaba en septiembre de 1787. En esta ocasión la referencia es sobre la Sterwartia, planta que Linné había recibido de John Clayton (1694?-1773) y que había clasificado como Polyandria monogynia. Cavanilles recurría a las obras de Mark Catesby (1682-1749), Georg Dionys Ehret (1710-1770) y John Mitchell (ca. 1680-1772) para demostrar el error de Linné42.

La influencia decisiva de esta etapa en la definición profesional de Cavanilles quedó de manifiesto cuando a finales de 1787 regresó durante unos meses a España. Estancia que aprovechó para comentarle a Jussieu el estado en que se encontraba la botánica en nuestro país, centrándose en la situación del Real Jardín Botánico y en los trabajos en que estaban inmersos los botánicos españoles. Su definitiva conversión a la botánica queda reflejada en las palabras escritas a Jussieu: "Vous pouvez croire avec quel empressement j'ai visité ce jardin - [el Botánico madrileño\}—». Y al mismo tiempo, quedaba de manifiesto cómo echaba de menos los jardines franceses: «J'y ai trouvé de excelements commencements et tout magnifique, mais très peu des plantes en comparaison de votre jardin". Situación que Cavanilles encontraba compensada por el hallazgo de algunas plantas distintas de las de París, así como por el número de plantas nuevas que habían llegado del Perú enviadas por los componentes de la expedición hispanofrance$\mathrm{sa}^{43}$.

Durante su estancia en Madrid, Cavanilles reunió una colección de cerca de un millar de plantas, proporcionadas por botánicos españoles. Uno de ellos fue Miguel Barnades hijo, médico como su padre, que unos años después, en 1793, sustituiría a Antonio Palau como segundo catedrático del Jardín Botánico de Madrid. Cavanilles comunicaba a Jussieu que Barnades hijo había determinado, sin contar las criptógamas, 2.300 plantas, especialmente gramíneas, entre las que se encontraban un gran número de especies nuevas. La intención de Barnades era terminar y publicar la "Flora Hispánica», que había comenzado su padre, que esperaba completar con más de cien grabados que ya tenía dibujados ${ }^{44}$. Esta era la principal novedad que comentaba Cavanilles, en cuanto a trabajos botánicos. Por supuesto, Jussieu valoró como

\footnotetext{
42 Carta de Cavanilles a Jussieu, París, 22 de septiembre de 1787; Laboratoire de Phanérogamie (MNHN).

${ }^{43}$ Carta de Cavanilles a Jussieu, Madrid, 29 de noviembre de 1787; Laboratoire de Phanérogamie (MNHN).

${ }^{44}$ Carta de Cavanilles a Jussieu, Madrid, 25 de febrero de 1788; Laboratoire de Phanérogamie (MNHN).
} 
muy interesante esta posibilidad, que abría nuevos espacios al conocimiento de la vegetación española ${ }^{45}$.

Durante los meses que permaneció en Madrid, Cavanilles trabajó junto con Barnades hijo, clasificando su colección de plantas españolas, entre las cuales había varias especies nuevas. Esperaba que Jussieu las examinara y rectificara su nomenclatura a su llegada a París ${ }^{46}$.

Cavanilles volvió a París avanzado el año 1788. En esta ocasión, su estancia en la capital se vio limitada prácticamente a un año, debido a la inestabilidad política provocada por la revolución. Durante este lapso de tiempo, salieron de las imprentas parisinas sus penúltimas disertaciones sobra la Monadelphia.

\section{El regreso definitivo a España}

En octubre de 1789, Cavanilles envía a Jussieu su última carta desde París, despidiéndose, puesto que pensaba partir hacia España al día siguiente. El nivel de relación que habían alcanzado quedaba de manifiesto en su disculpa por no haberle hecho una última visita. La revolución y la rotura de su "calotin" [bonete] —decía un tanto jocosamente- le habían retenido "prisionero" en su casa, ya que no había querido exponerse a los sarcasmos del pueblo $^{47}$. Cavanilles, disfrazado y ocultándose, abandonó definitivamente París.

La distancia física y las diferencias científicas y políticas que se abrieron entre ambos naturalistas, no fue obstáculo para que se continuara manteniendo una relación epistolar hasta comienzos del siglo XIX.

Una de las mayores limitaciones en la continuidad de la correspondencia fue ocasionada por las ocupaciones políticas, originadas a raíz de la nueva situación política creada en Francia. Tras la Revolución, Jussieu intervino activamente en la política de su país, siendo encargado de organizar los hospitales y hospicios de su departamento, lo que le impedía dedicarle más tiempo a los estudios botánicos. Mas adelante, en 1793, con la reorganización del jardín y el establecimiento del Muséum National d'Histoire Naturelle formó parte del consejo administrativo y fue nombrado director de esta institución científica.

Cavanilles por su parte, desde su regreso definitivo a España, se dedicó intensamente al estudio de la historia natural, particularmente de la botáni-

\footnotetext{
45 Carta de Jussieu a Cavanilles, París, 23 de marzo de 1788; ARJB, XIII, 3, 32, 9.

46 Carta de Cavanilles a Jussieu, Madrid, 3 de marzo de 1788; Laboratoire de Phanérogamie (MNHN).

47 Carta de Cavanilles a Jussieu, París, 10 de octubre de 1789; Laboratoire de Phanérogamie (MNHN).
} 


\section{FRANCISCO PELAYO Y MARCELO FRIAS}

ca. Terminó con su trabajo de revisión y publicación de la Monadelphia, publicando los dos últimos tomos que quedaban pendientes, la 9. ${ }^{\mathrm{a}}$ y la $10 .^{\mathrm{a}}$ disertaciones, que había acabado durante su estancia en la capital francesa pero que fueron editados en Madrid. Había comenzado ya a trabajar en su siguiente obra botánica, los Icones et descriptiones plantarum, y al poco tiempo fue comisionado para reconocer y describir la historia natural de España, que iniciaría por la Comunidad de Valencia.

La relación epistolar de Cavanilles con Jussieu perteneciente a este segundo período -1789 a 1802 - se caracteriza por una continua solicitud del valenciano para que el botánico francés comprobara todas aquellas plantas que quería publicar en sus Icones sobre las que tenía dudas.

En marzo de 1790 Cavanilles escribía a Jussieu comunicándole que acababa de terminar las dos últimas disertaciones de su Monadelphia y el prólogo general a toda la obra, que saldría en la segunda edición ese mismo año. En este trabajo, aunque citaba con elogio el método natural, justificaba su elección del sistema sexual de Linné, por el que se había sentido inclinado desde sus comienzos en la disciplina.

Por esta fechas - principios de 1790 - Cavanilles ya se encontraba bastante distanciado de Lamarck. Su relación con este naturalista había sido anterior a la mantenida con A. L. de Jussieu ${ }^{48}$. Aunque en los primeros tiempos de su estancia en París sus relaciones debieron de ser afectuosas, con el paso del tiempo las diferencias profesionales y el carácter de Lamarck fueron provocando un alejamiento entre ambos naturalistas. Cavanilles criticaba a Lamarck en su 9. ${ }^{a}$ disertación botánica, a propósito del género Banisteria, en donde había salido en defensa de Linné. Cavanilles se sentía indignado por la actitud de Lamarck, que había copiado sus manuscritos sin comunicárselo y redactado con ellos sus artículos sobre la Hugonia y la Hermannia. Peor debía ser la opinión sobre Lamarck que tenía el botánico inglés James Edward Smith, quien, según Cavanilles, había tildado al naturalista francés de crítico miserable con todos los que valían más que él ${ }^{49}$.

Jussieu, mientras tanto, tenía otras preocupaciones, muy alejadas de la botánica. Contestaba a Cavanilles, quien, como hemos señalado, le había solicitado su opinión acerca de diversas plantas y que se manifestaba contrariado por la falta de respuesta, describiéndole el agitado ambiente político que se respiraba en la Francia revolucionaria:

\footnotetext{
48 Cf. Viera y Clavijo (1849), p. 95: «Trato con amistad a M. de Lamarck y muy pronto espero hacer lo mismo con Jussieu.»

49. Carta de Cavanilles a Jussieu, Madrid, 6 de marzo de 1790; Laboratoire de Phanérogamie (MNHN).
} 


\title{
ANTONIO JOSE CAVANILLES Y LA HISTORIA NATURAL FRANCESA
}

\begin{abstract}
"Nous sommes toujours ici, mon cher, dans une grande fermentation politique. Tout l'Ancien Regime est reformé dans toutes les parties. Il en resulte que les états et les conditions sont bouleversés. Toute la judicature est renouvellée, ou va l'etre incéssamment. Les charges vénales sont supprimées. Nos juges, nos officiers municipaux, nos dignataires ecclesiastiques, seront élus par un corps d'électeurs établi dans chaque département. Las sciences et les savants sont assez tranquilles au milieu de ces mouvements et je présume que le nouveau régime leur sera favorable. ${ }^{50}$
\end{abstract}

Aprovechaba Jussieu esta misma carta para insistirle a Cavanilles sobre la conveniencia de adoptar su método de disposición de plantas agrupándolas en familias naturales, más preferible que el de los «órdenes sistemáticos». Esperaba que Cavanilles se convenciera de esta propuesta y que transmitiera este convencimiento a sus colegas españoles. Y sostenía: " c'est la veritable Science dont l'ancienne n'est qu'une table méthodique ${ }^{51}$. Los botánicos, continuaba Jussieu, debían trabajar en esta línea para perfeccionarla, en lugar de perder el tiempo concentrándose en los sistemas arbitrarios.

La respuesta de Cavanilles ante estas sugerencias no se hizo esperar. La contundencia de la misma dejaba muy en claro su posición sobre la cuestión planteada. Cavanilles replicaba al botánico francés, anunciándole en primer lugar que desde. su llegada a España trabajaba en dos obras, los Icones plantarum... y una «Flora Matritensis». Sin embargo, debido al volumen de plantas de que constaba ya su herbario -más de mil ejemplares de toda la península - estaba planteándose la posibilidad de trabajar en la descripción de una flora de España, lo más completa posible. El problema es que se partía prácticamente de cero, sin el auxilio de ningúna obra que recogiera el estudio de floras parciales, puesto que la obra de José Quer, continuada por Casimiro Gómez Ortega, le parecía lamentable y consideraba que no servía para nada ${ }^{52}$. Además, Barnades hijo no había podido publicar su trabajo debido a problemas económicos y por otras diversas dificultades.

En cuanto al tema que Jussieu le había planteado, sobre la forma de clasificar las plantas, Cavanilles le recordaba que él ya se había pronunciado muy claro en su obra sobre las Monadelphia. Pensaba que tanto para los que se iniciaban en el estudio de la botánica como para otros muchos con conocimientos en esta disciplina, la sistemática linneana era preferible al método natural, y más sobre todo siendo éste último aún muy defectuoso. Dudaba incluso que el método natural proporcionara alguna ventaja para los naturalistas expertos en botánica. En el caso de sus compatriotas, señalaba que el

\footnotetext{
${ }^{50}$ Carta de Jussieu a Cavanilles, París, 9 de septiembre de 1790; ARJB, XIII, 3, 32, 16.

${ }^{51}$ Idem.

52 Carta de Cavanilles a Jussieu, Madrid, 26 de septiembre de 1790; Laboratoire de Phanérogamie (MNHN).
} 
tema estaba más claro aún, ya que el único al que podía llamarse botánico era Palau y era un linneano declarado ${ }^{53}$. Afirmación que arroja ciertas sombras al no encontrarse referencia alguna a Barnades.

Al mismo tiempo, Cavanilles siguió mostrando su enojo contra Lamarck. Críticas que fue señalando durante toda la década de los años 90 en su correspondencia con Jussieu. Pero al mismo tiempo, seguía reconociendo el valor de sus trabajos y quizás fruto de su antigua amistad fuera el que manifestara su enfado hacia Smith. Este, como señalamos anteriormente, se había mostrado muy crítico con Lamarck. Cavanilles, aún entendiendo las razones de Smith, no compartía la forma en que atacaba a Lamarck ${ }^{54}$. Con todo, la actitud de Cavanilles quedó definida en el hecho de que Lamarck quedara excluido del grupo de franceses a los que enviaba sus materiales ${ }^{55}$.

\section{Consideraciones finales}

De 1802 es la última referencia que conservamos del intercambio de Cavanilles con Jussieu. Para entonces, el botánico español ya se encontraba al frente de la dirección del Real Jardín Botánico madrileño. En un corto período de tiempo reorganizó esta institución, proponiendo entre otros objetivos centralizar los materiales botánicos de las diferentes expediciones científicas y modificar la orientación linneana ortodoxa de la enseñanza.

La formación de Cavanilles en Francia y su relación con el mundo de la Historia Natural del país vecino le acercó a naturalistas críticos con Linné y su sistema artificial - Lamarck, Jussieu-. Sin embargo, Cavanilles se había ido decantando por el botánico sueco, aunque reduciendo el número de sus clases. Respecto a Jussieu, y a pesar de la distancia profesional, mantuvo una relación personal que se alargó casi durante una veintena de años. En cambio, con Lamarck el distanciamiento fue tanto profesional como personal. El paso de Cavanilles por Francia y las relaciones con los científicos del país vecino nos permite avanzar en la comprensión de las ideas que aplicó a su concepción del trabajo botánico. Una labor que no se fundamenta en la identidad del método adoptado, es decir, las familias naturales propuestas por los botánicos franceses, sino en la crítica abierta y constructiva de dicho método.

\footnotetext{
53 Idem.

${ }^{54}$ Ver, por ejemplo, carta de Cavanilles a Jussieu, Madrid, 26 de septiembre de 1790; Laboratoire de Phanérogamie (MNHN).

${ }^{55}$ Carta de Cavanilles a Jussieu, Madrid, 21 de febrero de 1791; Laboratoire de Phanérogamie (MNHN): «a todos, menos a Lamarck».
} 